\title{
Worldwide Preferences for Natural Remedies for "Nervousness" and Common Colds
}

\author{
Mary V. Seeman ${ }^{1^{*}}$, Neil Seeman ${ }^{2,3,4}$, Jason A. Cho ${ }^{4}$ \\ ${ }^{1}$ Department of Psychiatry, University of Toronto, Toronto, ON M5P 3L6, \\ Canada; \\ ${ }^{2}$ Institute For Health Policy, Management \& Evaluation, University Of Toronto, \\ 155 College Street, Toronto, Ontario M5T 3M7, Canada; \\ ${ }^{3}$ Senior Fellow, Massey College, University Of Toronto, 4 Devonshire Place, \\ Toronto, Ontario M5S 2E1, Canada; \\ ${ }^{4}$ RIWI Corp., 459 Bloor Street West, Suite 200, Toronto, Ontario M5S 1X9, \\ Canada.
}

*Correspondence: Mary V. Seeman MD, Professor Emerita, Department of Psychiatry, University of Toronto, ON M5P 3L6, Canada.

JOURNAL OF PSYCHIATRY AND BRAIN SCIENCE Email: mary.seeman@utoronto.ca.

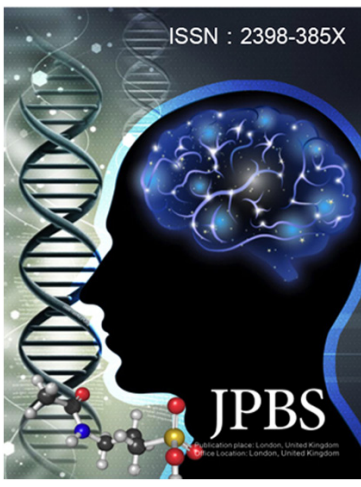

http://jpbs.qingres.com

\section{fOPEN ACCESS}

DOI: 10.20900/jpbs.20180001

Received: January 5, 2018

Accepted: February 23, 2018

Published: February 25, 2018

Copyright: (2018 Cain et al. This is an open access article distributed under the terms of the Creative Commons Attribution License, which permits unrestricted use, distribution, and reproduction in any medium, provided the original author and source are credited.

\begin{abstract}
In order to assess the prevalence of use of natural remedies for "nervous" disorders, a global random online survey was conducted in July 2017 using RDITTM sampling methodology. There were 75,101 respondents worldwide. For both nervousness and common colds, the preference was for natural plant remedies over prescription drugs, with at least a 3:2 margin for most of the 50 countries surveyed. The preference for natural products was not restricted to any specific demographic although respondents over age 65 were less likely than younger respondents to endorse this preference. The two countries that were exceptions to this general observation were Japan and Thailand, and the reasons for this are probed in the discussion. Despite known safety hazards of natural remedies, their use has become a universal phenomenon.
\end{abstract}

Key Words: Alternative; Complementary; Herbal; Supplemental; Nervousness; Drugs 


\section{INTRODUCTION}

The word "natural" is associated in people's minds with purity and safety ${ }^{[1]}$, which may be why, when ill, many of us prefer to self-treat with natural products rather than seek prescriptions from doctors. This is true despite the fact that, in most countries, natural remedies are not covered by national insurance ${ }^{[2]}$. Of particular interest to psychiatry is the reportedly high use of complementary medicines among individuals who meet criteria for mental disorders ${ }^{[3]}$. Over the past few years, those who self-identify as suffering from stress have increasingly turned to herbal remedies ${ }^{[4]}$. Perhaps paradoxically, the greater the severity of the self-reported anxiety, the more enthusiastic the endorsement of herbal medicines. This may be because conventional therapies have not worked well for the severely and chronically anxious ${ }^{[5,6]}$.

There are undoubtedly reasons why some individuals rely more on natural remedies than on pharmaceuticals. Pharmaceutical products are negatively viewed by many as symbols of unwanted modernity, capitalism, industrialization, urbanization, globalization, Westernization and/or technology. It may be a point of pride to express a preference for traditional medicines, a way of establishing one's identity perhaps, and distinguishing oneself from the mainstream ${ }^{[7,8]}$. If this were the case, differences in preference for natural remedies should distinguish some countries from others.

We were interested to see whether a preference for natural remedies held true for the treatment of anxiety or, in popular language, "nervousness ". We wanted to know whether people living in different regions of the world would show such a preference to different degrees and whether it would manifest differently in individuals of different educational background, in men and women, the young and the elderly.

\section{METHODS}

In July 2017, we conducted a 50-country online survey asking random respondents about their preferences for natural remedies versus prescriptions for "nervous conditions" and for a control condition, the common cold. We used the global sampling methodology, Random Domain Intercept Technology (RDITTM). Exposure to our questions is triggered when Web users manually type in a lapsed or dormant Website destination (e.g., www.phoneyurl.com) into the Web address (URL) bar $^{[9,10]}$. When Web users land on a RDIT-controlled website, we are able to collect response data that are totally anonymous. The method encourages quick, instinctive answers from random individuals who are not self-selected survey takers and who have no incentive to respond other than a curiosity about the questions posed. The methodology has been previously used to measure global mental health stigma ${ }^{[11]}$ and also the prevalence of suicidal ideas on college campuses ${ }^{[12]}$. It has shown high test-retest reliability in global surveys ${ }^{[13]}$ as long as the questions that are posed are relatively few, short, and straightforward.

In the dominant language of each targeted country, we asked the age, gender, and education level of respondents, and we posed the following two questions:

1. If cost and ease of purchase were identical, for a cold, would you prefer a prescription drug or a natural product? (Select one or the other)

2. If cost and ease of purchase were identical, for feeling nervous, would you prefer a prescription drug or a natural product? (Select one or the other)

\section{RESULTS}

We received 62,823 full responses from 50 countries. No major differences were found between colds and nervous conditions. For both conditions, respondents preferred natural products by an almost 3:2 margin in 46 out of 50 countries (Tables $1 \& 2$ ). Japan and Thailand were the only two countries that endorsed a preference for prescription drugs for both feelings of nervousness and for colds (Fig. 1 \& Fig. 2). South Koreans showed a preference for prescription drugs for colds and split 50:50 when it came to nervous conditions. Respondents from Mexico were equally interested in natural and prescription drugs for both conditions. Men and women did not differ in their preferences, neither did people from different educational backgrounds. For nervousness only, respondents over 65 were $6 \%$ less in favor of natural products than were younger respondents. 
Table 1. Q1 - If cost and ease of purchase were identical, for a cold, would you prefer a prescription drug or a natural product? (Weighted responses, source: US Census Bureau IDB)

\begin{tabular}{|c|c|c|c|}
\hline Country & Prescription Drug & Natural Product & Respondents \\
\hline Algeria & $41 \%$ & $59 \%$ & 1332 \\
\hline Argentina & $45 \%$ & $55 \%$ & 1383 \\
\hline Australia & $36 \%$ & $64 \%$ & 1616 \\
\hline Bangladesh & $40 \%$ & $60 \%$ & 1781 \\
\hline Brazil & $31 \%$ & $69 \%$ & 1831 \\
\hline Canada & $37 \%$ & $63 \%$ & 1580 \\
\hline Chile & $35 \%$ & $65 \%$ & 1240 \\
\hline China & $34 \%$ & $66 \%$ & 1283 \\
\hline Colombia & $31 \%$ & $69 \%$ & 1357 \\
\hline Egypt & $42 \%$ & $58 \%$ & 1368 \\
\hline Finland & $42 \%$ & $58 \%$ & 1319 \\
\hline France & $29 \%$ & $71 \%$ & 1486 \\
\hline Germany & $34 \%$ & $66 \%$ & 1705 \\
\hline Greece & $29 \%$ & $71 \%$ & 1140 \\
\hline Hungary & $28 \%$ & $72 \%$ & 1382 \\
\hline India & $20 \%$ & $80 \%$ & 2563 \\
\hline Indonesia & $34 \%$ & $66 \%$ & 1681 \\
\hline Iran & $31 \%$ & $69 \%$ & 1393 \\
\hline Iraq & $43 \%$ & $57 \%$ & 1322 \\
\hline Italy & $41 \%$ & $59 \%$ & 1265 \\
\hline Japan & $57 \%$ & $43 \%$ & 1364 \\
\hline Kenya & $32 \%$ & $68 \%$ & 1418 \\
\hline Korea, South & $51 \%$ & $49 \%$ & 1722 \\
\hline Malaysia & $34 \%$ & $66 \%$ & 1271 \\
\hline Mexico & $49 \%$ & $51 \%$ & 1708 \\
\hline Morocco & $44 \%$ & $56 \%$ & 1338 \\
\hline Nigeria & $36 \%$ & $64 \%$ & 1738 \\
\hline
\end{tabular}




\begin{tabular}{|c|c|c|c|}
\hline Pakistan & $42 \%$ & $58 \%$ & 1711 \\
\hline Peru & $38 \%$ & $62 \%$ & 1463 \\
\hline Philippines & $27 \%$ & $73 \%$ & 1828 \\
\hline Poland & $38 \%$ & $62 \%$ & 1327 \\
\hline Portugal & $36 \%$ & $64 \%$ & 1230 \\
\hline Romania & $34 \%$ & $66 \%$ & 1339 \\
\hline Russia & $37 \%$ & $63 \%$ & 1438 \\
\hline Saudi Arabia & $48 \%$ & $52 \%$ & 1254 \\
\hline Serbia & $35 \%$ & $65 \%$ & 1346 \\
\hline South Africa & $21 \%$ & $79 \%$ & 1408 \\
\hline Spain & $41 \%$ & $59 \%$ & 1471 \\
\hline Sudan & $48 \%$ & $52 \%$ & 1463 \\
\hline Syria & $41 \%$ & $59 \%$ & 1276 \\
\hline Taiwan & $47 \%$ & $53 \%$ & 1662 \\
\hline Thailand & $55 \%$ & $45 \%$ & 1617 \\
\hline Tunisia & $48 \%$ & $52 \%$ & 1176 \\
\hline Turkey & $41 \%$ & $59 \%$ & 2478 \\
\hline Uganda & $29 \%$ & $71 \%$ & 1428 \\
\hline Ukraine & $37 \%$ & $63 \%$ & 1625 \\
\hline United Kingdom & $35 \%$ & $65 \%$ & 1473 \\
\hline United States & $34 \%$ & $66 \%$ & 1575 \\
\hline Venezuela & $41 \%$ & $59 \%$ & 1489 \\
\hline Vietnam & $42 \%$ & $58 \%$ & 1438 \\
\hline
\end{tabular}

Table 2. Q2 - If cost and ease of purchase were identical, for feeling nervous, would you prefer a prescription drug or a natural product? (Weighted responses, source: US Census Bureau IDB)

\begin{tabular}{lccc}
\hline Country & Prescription Drug & Natural Product & Respondents \\
\hline Algeria & $40 \%$ & $60 \%$ & 1160 \\
Argentina & $40 \%$ & $60 \%$ & 1193 \\
Australia & $33 \%$ & $67 \%$ & 1302 \\
Bangladesh & $43 \%$ & $57 \%$ & 1321 \\
Brazil & $31 \%$ & $69 \%$ & 1650 \\
\hline
\end{tabular}




\begin{tabular}{|c|c|c|c|}
\hline Canada & $37 \%$ & $63 \%$ & 1266 \\
\hline Chile & $30 \%$ & $70 \%$ & 1083 \\
\hline China & $33 \%$ & $67 \%$ & 1117 \\
\hline Colombia & $29 \%$ & $71 \%$ & 1162 \\
\hline Egypt & $39 \%$ & $61 \%$ & 1194 \\
\hline Finland & $43 \%$ & $57 \%$ & 1052 \\
\hline France & $29 \%$ & $71 \%$ & 1280 \\
\hline Germany & $36 \%$ & $64 \%$ & 1385 \\
\hline Greece & $27 \%$ & $73 \%$ & 1011 \\
\hline Hungary & $27 \%$ & $73 \%$ & 1161 \\
\hline India & $20 \%$ & $80 \%$ & 2041 \\
\hline Indonesia & $29 \%$ & $71 \%$ & 1473 \\
\hline Iran & $24 \%$ & $76 \%$ & 1216 \\
\hline Iraq & $44 \%$ & $56 \%$ & 1107 \\
\hline Italy & $34 \%$ & $66 \%$ & 1022 \\
\hline Japan & $58 \%$ & $42 \%$ & 1200 \\
\hline Kenya & $34 \%$ & $66 \%$ & 1143 \\
\hline Korea, South & $50 \%$ & $50 \%$ & 1458 \\
\hline Malaysia & $30 \%$ & $70 \%$ & 1041 \\
\hline Mexico & $50 \%$ & $50 \%$ & 1468 \\
\hline Morocco & $46 \%$ & $54 \%$ & 1175 \\
\hline Nigeria & $43 \%$ & $57 \%$ & 1340 \\
\hline Pakistan & $43 \%$ & $57 \%$ & 1295 \\
\hline Peru & $36 \%$ & $64 \%$ & 1279 \\
\hline Philippines & $29 \%$ & $71 \%$ & 1524 \\
\hline Poland & $35 \%$ & $65 \%$ & 1101 \\
\hline Portugal & $36 \%$ & $64 \%$ & 1005 \\
\hline Romania & $29 \%$ & $71 \%$ & 1155 \\
\hline Russia & $34 \%$ & $66 \%$ & 1209 \\
\hline Saudi Arabia & $47 \%$ & $53 \%$ & 1032 \\
\hline Serbia & $33 \%$ & $67 \%$ & 1159 \\
\hline South Africa & $24 \%$ & $76 \%$ & 1190 \\
\hline Spain & $37 \%$ & $63 \%$ & 1144 \\
\hline Sudan & $45 \%$ & $55 \%$ & 1202 \\
\hline Syria & $36 \%$ & $64 \%$ & 1139 \\
\hline Taiwan & $41 \%$ & $59 \%$ & 1422 \\
\hline Thailand & $58 \%$ & $42 \%$ & 1321 \\
\hline Tunisia & $45 \%$ & $55 \%$ & 1029 \\
\hline Turkey & $39 \%$ & $61 \%$ & 2068 \\
\hline
\end{tabular}




\begin{tabular}{llll}
\hline Uganda & $38 \%$ & $62 \%$ & 1107 \\
Ukraine & $39 \%$ & $61 \%$ & 1360 \\
United Kingdom & $33 \%$ & $67 \%$ & 1276 \\
United States & $32 \%$ & $68 \%$ & 1257 \\
Venezuela & $40 \%$ & $60 \%$ & 1313 \\
Vietnam & $40 \%$ & $60 \%$ & 1215 \\
\hline
\end{tabular}

Q1 - If cost and ease of purchase were identical, for a cold, would you prefer a prescription drug or a natural product? (Weighted responses, 50 countries)
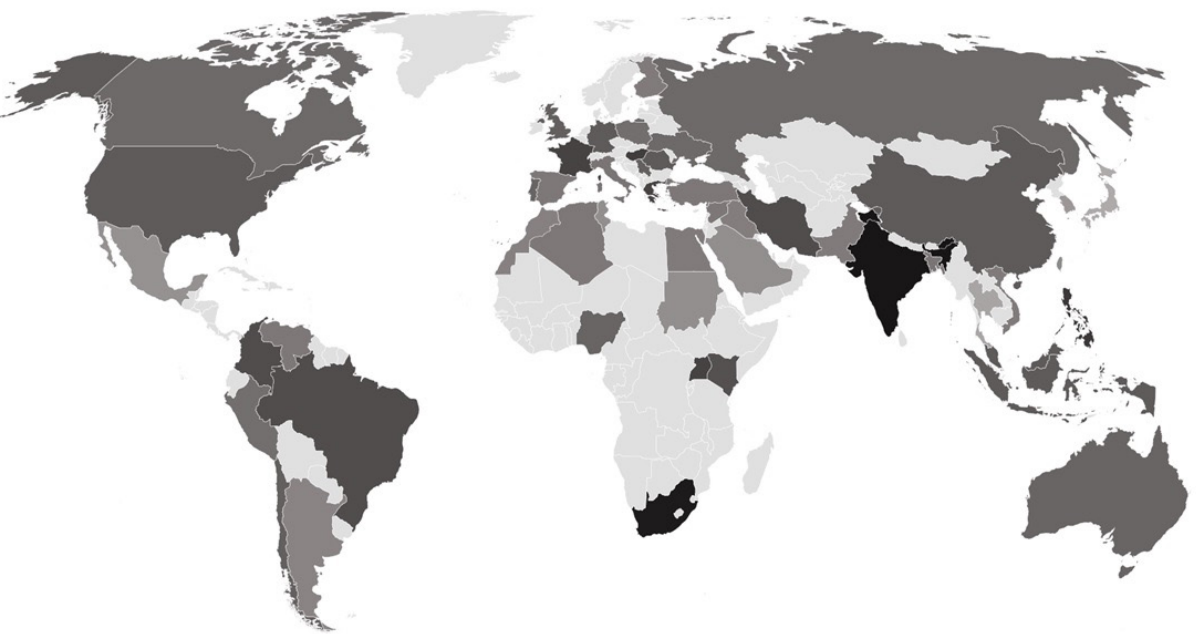

Fig. $1 \mathrm{Q} 1$ - If cost and ease of purchase were identical, for a cold, would you prefer a prescription drug or a natural product? (Weighted responses, source: US Census Bureau IDB)

Q2 - If cost and ease of purchase were identical, for feeling nervous, would you prefer a prescription drug or a natural product? (Weighted responses, 50 countries)
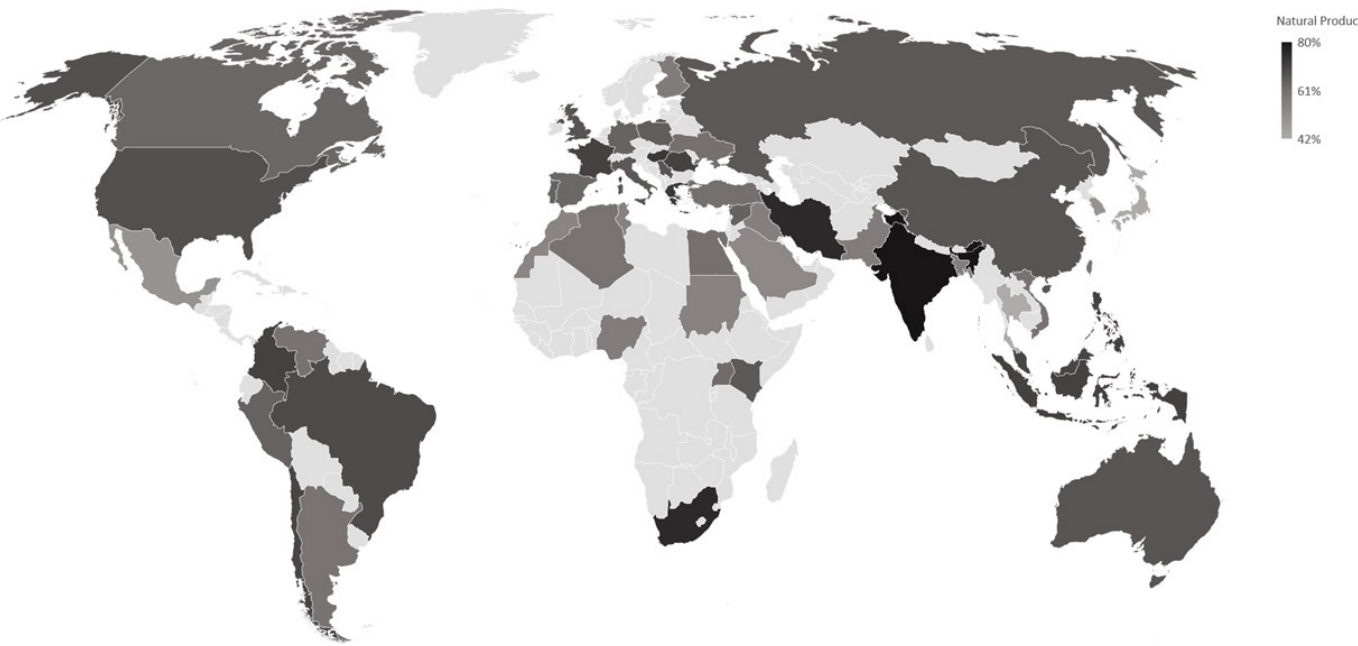

Fig. 2 Q2 - If cost and ease of purchase were identical, for feeling nervous, would you prefer a prescription drug or a natural product? (Weighted responses, source: US Census Bureau IDB) 


\section{DISCUSSION}

The results of the survey show a decided $3: 2$ preference for natural products for both nervousness and for colds. Our purpose had been to compare the use of natural remedies for nervousness versus their use in a minor condition such as the common cold since the medical literature suggests that herbal products are mainly used to treat conditions subjectively perceived as minor. We reasoned that nervous complaints, because they are stigmatized in many parts of the world, would be more likely than would a cold to be self-treated. This turned out not to be the case. The literature cites echinacea, Chinese herbal cold and allergy products, elderberry extracts, andrographis paniculata, pelargonium sidoides and acanthopanax senticosus as potentially effective treatments for colds ${ }^{[14-17]}$ and as many as 27 types of herbs for nervous conditions, the most common of which are St John's wort, kava, valerian, hops, passionflower, and ginkgo biloba ${ }^{[18,19]}$.

Almost all the countries we surveyed preferred natural products to prescribed drugs for both conditions. Japan and Thailand stand out as preferring prescription drugs for the two conditions while South Korea and Mexico endorsed both types of treatment equally.

With respect to Japan, herbal medicine, along with medicines derived from animals and minerals, play a large part in the Japanese personalized holistic treatment system called Kampo (from Kan for Chinese, po for system). In 2001, Kampo was incorporated into the curriculum of medical schools throughout the country ${ }^{[20]}$ and over twenty different Kampo medicines are listed in the Japanese pharmacopoeia ${ }^{[21]}$. Almost $90 \%$ of Japanese doctors are said to prescribe Kampo medicines ${ }^{[22,23]}$ on the basis of sho, the Kampo diagnostic system. Herbal preparations in Japan can either be sold as over-thecounter preparations, or as prescriptions. In contrast to western medicine, the goal of treatment is not to abolish symptoms but to restore harmony within the person and between the person and his or her environment ${ }^{[24]}$. This goal is the same for Chinese and Korean medicines but, in those two countries, there are traditional medicine doctors who prescribe only traditional herbal medicines and western medicine doctors who prescribe only western medicines. In Japan, by contrast, medical doctors who have been trained in western methods often prescribe Kampo. This may explain the survey's seemingly discrepant results for Japan.

The only other country, besides Japan, that preferred prescribed medicine was Thailand. Thai Traditional Medicine (TTM), the mainstream medical system in Thailand until 1888, while currently available in many modern hospitals in Thailand, is not well integrated with modern medical practices in the country ${ }^{[25]}$. Although TTM is used in the rural areas of Thailand, those who live in urban centers tend to dismiss it as unscientific ${ }^{[26]}$. This point is underscored in The World Health Report on complementary medicine in Thailand ${ }^{[27]}$ and may help to explain our findings.

Despite the fact that the literature reports that herbs are more popular with women than with men ${ }^{[2,28,29]}$, our survey found little difference. The literature reports that the middle aged are the demographic most likely to use natural products ${ }^{[2]}$. Our results show that respondents over 65 were not as interested in natural products for "nerves" as were younger respondents. At this age, the term "nerves" may signal something more serious than it does in younger age. Although those with more education have repeatedly been reported more likely to use herbal products than their less educated peers ${ }^{[28,30,}$ ${ }^{31]}$, we did not find this.

There are many possible reasons for preferring natural medicines, one being dissatisfaction with one's experience of physicians, with the relative ineffectiveness of previous medical treatment, with the perception of being offered no choice in a doctor's office, and, importantly, with the many adverse effects of conventional drugs. In a US mail survey of 1,035 respondents, all these issues were examined, and found insufficient to account for people's preferences ${ }^{[30]}$. Nevertheless, many reports highlight dissatisfaction with modern medicine's hurried consultations, over-emphasis on laboratory tests, and drug side effects that many find difficult to tolerate ${ }^{[32-34]}$. Standard medical claims that natural medicines are less effective than conventional drugs are based on the fact that they have not been proven effective in randomized double blind clinical trials. Different health traditions, however, do not define "effectiveness' in the same way. In Europe and North America, effectiveness is equated with the amelioration of the symptoms. Elsewhere, the effectiveness of a medication is judged by its ability to restore balance, to target the unique root causes of illness in a particular person, to prevent future problems in that person. That is where the effectiveness of alternative medicines are said to lie ${ }^{[35]}$. Effectiveness thus defined depends not only on the chemical content of a product but also on the context of its administration, which encompasses the beliefs and expectations of the recipient and the relationship between recipient and prescriber. The popularity of herbal treatment is said to depend to a large extent on the collaborative nature of alternative 
medicine, the generous time practitioners devote to their patients, the dialogue they enter into ${ }^{[36]}$. As a consequence, patients feel in control of their own health, a control they generally do not feel when visiting western doctors ${ }^{[36-39]}$. Alternative medicine practitioners are perceived as less authoritative, less coercive, allowing patients more autonomy in decision-making. They are also said to allow more family involvement, an important consideration for many who come from a tradition where health decisions are made by family elders. Alternative medicine practitioners are also perceived as more flexible, very willing to work with western doctors, while western doctors adamantly refuse to work with them ${ }^{[35]}$.

Based on the literature, one of the main explanations for choosing natural medicines is one of philosophical congruence. A firm belief in environmentalism, feminism, personal growth psychology and an interest in spirituality go along with a preference for natural remedies ${ }^{[39,40]}$. Taking natural substances when one is ill matches one's beliefs about the causation of illness, and is congruent with one's values, beliefs, and philosophical orientations ${ }^{[30,31,41]}$. For instance, nature is seen by many as benevolent and all that is natural is therefore seen as clean, pure, fresh, unpolluted, non-chemical and safe. There are also those who place a greater value on care than on cure. Among individuals who prefer natural remedies, there may be those who reject scientific authority and who believe strongly in freedom of choice. Adherents of natural medicine easily dismiss as flawed clinical trials that do not show a positive effect of the products they believe in. This comes from a philosophical belief that the whole exceeds the sum of the parts - that herbal formulations have a synergistic effect that cannot be demonstrated when studying one herb at a time ${ }^{[42]}$. Herbal remedies are understood to not target symptoms, but, rather, whole individuals at a particular juncture in the course of an illness. Any one remedy given at any one time is not expected to benefit everybody. For those in favor of alternative medicine, the evidence that is more persuasive than the evidence of clinical trials is that based on personal experience. It is buttressed by the conviction that, since most natural medicines have existed for centuries, they have been time-tested and proven safe, in contrast to new medicines, to which significant side effects emerge sometimes several years after launch.

In 2007, US adults spent $\$ 33.9$ billion on alternative medicines; nearly two-thirds went to the purchase of products, one third to practitioner visits ${ }^{[43]}$. There are other costs to the use of natural products. When an illness proves more serious than at first realized, dependence on such products may delay therapy that could have been more effective ${ }^{[42]}$. Some users may develop a sensitivity to herbal products. All drugs, including natural products, can cause adverse reactions if the dose is high and/or if the recipient experiences an idiosyncratic (allergic) reaction. Major concerns include the occasional development of anaphylaxis, asthma, urticaria, or contact dermatitis ${ }^{[44]}$. Because natural products are presumed by many to be entirely safe, women have been using them during pregnancy ${ }^{[45]}$, with unknown, potentially adverse, effects on the fetus.

As herbal usage grows, interaction with conventional drugs ${ }^{[46]}$ is becoming an increasingly prevalent problem, especially with respect to the interaction between certain herbs and anticoagulants. Bleeding may be excessive when an anticoagulant such as warfarin is combined with ginkgo (Ginkgo biloba), garlic (Allium sativum), dong quai (Angelica sinensis), or danshen (Salvia miltiorrhiza). Ginkgo also interacts with the antidepressant, trazodone ${ }^{[47,}$ ${ }^{48]}$. The most common interactions in psychiatry are with the herbal antidepressant, St. John's wort, which is a potent inducer of the liver enzyme, cytochrome P450 (CYP) 34A, and of the P-glycoprotein (PgP). St. John's wort may also inhibit or induce other CYPs, depending on the dose, route and duration of administration ${ }^{[49]}$. This herb decreases the blood concentrations of amitriptyline, an antidepressant, midazolam, an antianxiety medication, and methadone, a treatment for opiate addiction. It also triggers serotonin syndrome (high body temperature, agitation, increased reflexes, tremor, sweating, dilated pupils, and diarrhea) when co-administered with selective serotonin-reuptake inhibitors such as sertraline or paroxetine. While some herbal supplements have few interactions with prescribed drugs, some have been shown to be definitely unsafe, especially so in pregnant women and in children ${ }^{[49,50]}$.

In addition, there are risks of wrong handling and manufacturing that lead to herbal products being mislabeled, contaminated, or substituted. Studies of Ayurvedic preparations have uncovered contamination with potentially toxic levels of heavy metals including lead, mercury, and arsenic in more than $20 \%$ of samples ${ }^{[51,52]}$. A major concern is the lack of standardization among natural products. Moreover, in contrast to conventional pharmacotherapy, there is no comprehensive list of potential reactions that can be consulted when difficulties emerge. 


\section{LIMITATIONS}

The survey has several limitations. Only individuals with Internet access (skewed toward young males, the relatively well-to-do, and the better educated) during July 2017 were reached. Currently, only approximately $40 \%$ of the world has access to the Internet. Furthermore, in order to avoid burdening respondents with survey fatigue and increasing self-selection bias, only two health conditions were investigated. Comparisons of "nervousness" with conditions more serious than the common cold would have been interesting. It would also have been interesting to probe respondents' reasons for their choice. Since many conventional drugs (e.g. digitalis, reserpine, scopolamine, quinine) have been derived from herbs, and since doctors sometimes prescribe herbal preparations, the distinction between natural and prescription drugs may have been confusing to respondents. This may have been especially the case in Japan where herbal products are prescribed by physicians.

\section{REFERENCES}

1. Hartig T, Mitchell R, de Vries S, Frumkin H. Nature and health. Annu Rev Pub Health. 2014; 35: 207-228.

2. Frass $M$, Strassl RP, Friehs $H$, Müllner $M$, Kundi M, Kaye AD. Use and acceptance of complementary and alternative medicine among the general population and medical personnel: A systematic review. Ochsner J. 2012; 12(1): 4556.

3. Unützer J, Klap R, Sturm R, Young AS, Marmon T, Shatkin J, Wells KB. Mental disorders and the use of alternative medicine: results from a national survey. Am J Psychiatry. 2000; 157(11): 1851-1857.

4. Stein MB, Craske MG. Treating anxiety in 2017: Optimizing care to improve outcomes. JAMA. 2017; 318(3): 235-236.

5. Mclntyre E, Saliba AJ, Wiener KKK, Sarris J. Herbal medicine use behaviour in Australian adults who experience anxiety: a descriptive study. BMC Complement Altern Med. 2016; 16: 60.

6. Tawfiq RA, Nassar NN, El-Eraky WI, EI -Denshary ES. Enhanced efficacy and reduced side effects of diazepam by kava combination. J Advanc Res. 2014; 5(5): 587-594.

\section{CONCLUSION}

Survey respondents from almost all countries prefer natural medicines to prescriptions when treating nervous conditions, although no more so than when treating the common cold. No real difference in preference was found between men and women nor among the different levels of education of the respondents. The elderly were somewhat more in favor of conventional medicines for nervousness. Identity politics and philosophical leanings have been held responsible for biases toward or away from natural remedies, explanations that may perhaps underlie the results of this survey. A compelling conclusion, borne out by the relative lack of intercountry variability demonstrated in this study, is that the preference for natural remedies is broadly-based and, in an increasingly interconnected world, has become a universal phenomenon.

7. Gold CL, Clapp RA. Negotiating health and identity: lay healing, medicinal plants, and indigenous healthscapes in highland Peru. Latin Am Res Rev. 2011; 46(3): 93-111.

8. Wayland C. The failure of pharmaceuticals and the power of plants: Medicinal discourse as a critique of modernity in the Amazon. Soc Sci Med. 2004; 58(12): 2409-2419.

9. Seeman N, Ing A, Rizo S. Assessing and responding in real time to online anti-vaccine sentiment during a flu pandemic. Healthc $Q$. 2010; 13(Sppl): 8-15.

10. Seeman N, Fogler SG, Seeman MV. Mental health promotion through collection of global opinion data. J Prevent Med Care. 2016; 1(1): 23-36.

11. Seeman N, Tang S, Brown AD, Ing A. World survey of mental illness stigma. J Affect Disord. 2016; 190: 115-121.

12. Seeman N, Reilly DK, Fogler S. Suicide risk factors in U.S. college students: perceptions differ in men and women. Suicidol Online. 2017; 8(3): 24-30.

13. Seeman N. Use data to challenge mental-health stigma. Nature. 2015; 528(7582): 309. 
14. Ismail H, Schellack N. Colds and flu - an overview of the management. S Afr Fam Pract. 2017; 59(3): 5-12.

15. Mousa HA. Prevention and treatment of influenza, influenza-like illness, and common cold by herbal, complementary, and natural therapies. J Evid Based Complementary Altern Med. 2017; 22(1): 166-174.

16. Raal A, Volmer D, Sõukand R, Hratkevitš S, Kalle R. Complementary treatment of the common cold and flu with medicinal plantsresults from two samples of pharmacy customers in Estonia. PLoS One. 2013; 8(3): e58642.

17. Wright $\mathrm{Cl}$. Awareness of "Does Finiflu (containing garlic, onion and chili) provide symptomatic relief from cold and flu?" Curr Trends Nutraceut. 2016;1(1): 6 .

18. Gasparini M, Aurilia C, Lubian D, Testa M. Herbal remedies and the self-treatment of stress: An Italian survey. Eur J Integr Med. 2016; 8(4): 465470.

19. Sarris J, Panossian A, Schweitzer I, Stough C, Scholey A. Herbal medicine for depression, anxiety and insomnia: a review of psychopharmacology and clinical evidence. Eur Neuropsychopharmacol. 2011; 21(12): 841-860.

20. Payyappallimana $U$, Serbulea M. Integration of traditional medicine in the health system of Japan - policy lessons and challenges. Eur J Integ Med. 2013; 5(5): 399-409.

21. Okada T, Afendi FM, Yamazaki M, Nakahashi Chida K, Suzuki M, Kawai R, Kim M, Namiki T, Kanaya S, Saito K. Informatics framework of traditional Sino-Japanese medicine (Kampo) unveiled by factor analysis. J Nat Med. 2016; 70(1): 107-114.

22. Teng L, Zu Q, Li G, Yu T, Job KM, Yang X, Di L, Sherwin CM, Enioutina EY. Herbal medicines: challenges in the modern world. Part 3. China and Japan. Expert Rev Clin Pharmacol. 2016; 9(9): 1225-1233.

23. Watanabe S, Imanishi J, Satoh M, Ozasa K. Unique place of Kampo (Japanese traditional medicine) in complementary and alternative medicine: a survey of doctors belonging to the regional medical association in Japan. Tohoku $\mathrm{J}$ Exp Med. 2001; 194(1): 55-63.

24. Oka T. The role of Kampo (Japanese traditional herbal) medicine in psychosomatic medicine practice in Japan. Int Congr Series. 2006;
1287:304-308.

25. Jacobsen N, Salguero CP. Thai Herbal Medicine: Traditional Recipes for Health and Harmony. Findhorn Press; 2014.

26. Chotchoungchatchai $S$, Saralamp P, Jenjittikul T, Pornsiripongse S, Prathanturarug S. Medicinal plants used with Thai Traditional Medicine in modern healthcare services: A case study in Kabchoeng Hospital, Surin Province, Thailand. J Ethnopharmacol. 2012; 141(1): 193-205.

27. Subcharoen P, Chuthaputti A. Kingdom of Thailand. In: WHO Global Atlas of Traditional, Complementary and Alternative Medicine. Vol 2. Bodeker G, Ong CK, Grundy C, Burford G, Shein $\mathrm{K}$, editors. World Health Organization, the WHO Centre for Health Development, Kobe, Japan. 2005; pp.103-106.

28. Hanssen B, Grimsgaard S, Launsø L, Fønnebø V, Falkenberg T, Rasmussen NK. Use of complementary and alternative medicine in the Scandinavian countries. Scand J Prim Health Care. 2005; 23(1): 57-62.

29. Hori S, Mihaylov I, Vasconcelos JC, McCoubrie M. Patterns of complementary and alternative medicine use amongst outpatients in Tokyo, Japan. BMC Complement Altern Med. 2008; 8: 14.

30. Astin JA. Why patients use alternative medicine. JAMA. 1998; 279(19): 1548-1553.

31. O'Callaghan FV, Jordan N. Postmodern values, attitudes and the use of complementary medicine. Complement Ther Med. 2003; 11(1): 28-32.

32. Dinges M. Medical pluralism in Europe and India: Concept, historical background, perspectives. Ind J Res Homoeopath. 2017; 11(2): 118-122.

33. Paterson C, Britten N. "Doctors can't help much': the search for an alternative. $\mathrm{Br} \mathrm{J}$ Gen Pract. 1999; 49(445): 626-629.

34. Sirois FM, Gick ML. An investigation of the health beliefs and motivations of complementary medicine clients. Soc Sci Med. 2002; 55(6): 1025-1037.

35. Little CV. Simply because it works better: Exploring motives for the use of medical herbalism in contemporary U.K. health care. Complement Ther Med. 2009; 17(5-6): 300-308.

36. Truant T, Bottorff J. Decision making related to complementary therapies: a process of regaining control. Patient Educ Couns. 1999; 38(2): 131- 
142.

37. Andrews GJ. Private complementary medicine and older people: service use and user empowerment. Ageing Soc. 2002; 22(3): 343368.

38. Thorne S, Paterson B, Russell C, Schultz A. Complementary/alternative medicine in chronic illness as informed self-care decision making. Inter J Nurs Stud. 2002; 39(7): 671-683.

39. Siahpush M. Postmodern values, dissatisfaction with conventional medicine and popularity of complementary therapies. J Sociol. 1998; 34(1): 58-70.

40. Kelner M, Wellman B. Health care and consumer choice: medical and alternative therapies. Soc Sci Med. 1997; 45(2): 203-212.

41. Dodds S, Bulmer S, Murphy A. Consumer value in complementary and alternative medicine (CAM) health care services. Australas Market J. 2014; 22(3): 218-229.

42. Mainardi T, Kapoor S, Bielory L. Complementary and alternative medicine: Herbs, phytochemicals and vitamins and their immunologic effects. $\mathrm{J}$ Allergy Clin Immunol. 2009; 123(2): 283-294.

43. Nahin RL, Barnes PM, Stussman BJ, Bloom B. Costs of complementary and alternative medicine (CAM) and frequency of visits to CAM practitioners: United States, 2007. Natl Health Stat Report. 2009; 18: 1-14.

44. Heimall J, Bielory L. Defining complementary and alternative medicine in allergies and asthma: benefits and risks. Clin Rev Allergy Immunol. 2004; 27(2): 93-103.
45. Frawley J, Sibbritt D, Broom A, Gallois C, Steel A, Adams J. Women's attitudes towards the use of complementary and alternative medicine products during pregnancy. J Obs Gynaecol. 2016; 36(4): 462-467.

46. Fugh-Berman A. Herb-drug interactions. Lancet. 2000; 355(9198): 134-138.

47. Galluzi S, Zanetti O, Binetti G, Trabucchi M, Frisoni GB. Coma in a patient with Alzheimer's disease taking low dose trazodone and ginkgo biloba. J Neurol Neurosurg Psych. 2000; 68(5): 679-683.

48. Abad MJ, Bedoya LM, Bermejo P. An update on drug interactions with the herbal medicine Ginkgo biloba. Curr Drug Metab. 2010; 11(2): 171-181.

49. Zhou S, Chan E, Pan SQ, Huang M, Lee EJ. Pharmacokinetic interactions of drugs with $\mathrm{St}$ John's wort. J Psychopharmacol. 2004; 18(2): 262-276.

50. Asher GN, Corbett AH, Hawke RL. Common herbal dietary supplement-drug interactions. Am Fam Physician. 2017; 96(2): 101-107.

51. Saper RB, Kales SN, Paquin J, Burns MJ, Eisenberg DM, Davis RB, Phillips RS. Heavy metal content of ayurvedic herbal medicine products. JAMA. 2004; 292(23): 2868-2873.

52. Saper RB, Phillips RS, Sehgal A, Khouri N, Davis RB, Paquin J, Thuppil V, Kales SN. Lead, mercury, and arsenic in US- and Indianmanufactured Ayurvedic medicines sold via the Internet. JAMA. 2008; 300(8): 915-923. 